\title{
Research on the Properties of High-strength Gypsum Based Tile Adhesive in Interior Decoration
}

\author{
Ji Xiu Zhang, Ye Zhang, Ji Kang Liu, Yuan Chao Miao, Sai Hong Duan \\ National Key Laboratory of Solid Waste Resource Utilization and Energy-saving Building Materials \\ Beijing Building Materials Academy of Sciences Research, Beijing, 100041, China
}

\begin{abstract}
In this paper, a new early strength tile adhesive is prepared by using $\alpha$ - high strength gypsum and its properties are discussed. The research methods refer to relevant Chinese standards. The results show that the tensile bond strength of the adhesive can reach $0.6 \mathrm{MPa}$ in one day and $1.5 \mathrm{MPa}$ in 7 days, which is close to $80 \%$ of 28 -day strength. It is indicating that the adhesive has high bond strength, rapid strength development, and high dimensional stability. It effectively solves the problems that the traditional cement-based tile adhesive is prone to hollowing, falling off, and cracking. Additionally, no interface treatment is required during the using process of this gypsum-based adhesive.
\end{abstract}

\section{Introduction}

Tiles are important home decoration materials in China. With the increasing progress of ceramic tile production technology, the appearance and quality of ceramic tiles have three obvious changes ${ }^{[1-3]}$. Firstly, the size is getting larger and larger, from the original $300 \mathrm{~mm}$ or $600 \mathrm{~mm}$ to today's $800 \mathrm{~mm}$ or even $1000 \mathrm{~mm}$. Secondly, its thickness is gradually reduced from $8 \mathrm{~mm}-15 \mathrm{~mm}$ to $5 \mathrm{~mm}-8 \mathrm{~mm}$ and becomes thinner and thinner. Thirdly, the density of the tiles is getting higher and higher, closer to glass and the water absorption is getting lower and lower. These changes in tiles make higher requirements for auxiliary materials such as its matching adhesive between tiles and wall substrates ${ }^{[4]}$. The matching adhesive needs to have good dimensional stability, higher bond strength, and it is not easy to fade and frost ${ }^{[5-6]}$. In this paper, the desulfurized gypsum-based adhesive is prepared for indoor application of various tiles such as ceramic tiles, vitrified tiles, and stone. And no interface treatment is required during the construction bond process. The properties of the gypsum-based adhesive are detail discussed.

\section{Experimental}

\subsection{Materials}

Table 1 The mechanical properties of $\alpha$ - high strength gypsum

\begin{tabular}{cccccc}
\hline $\begin{array}{c}\alpha \text {-gypsum } \\
{[\mathrm{g}]}\end{array}$ & $\begin{array}{c}\text { Water } \\
\text { requirement[[\%] }\end{array}$ & $\begin{array}{c}\text { Initial setting } \\
\text { time } \\
{[\mathrm{min}]}\end{array}$ & $\begin{array}{c}\text { Final setting } \\
\text { time } \\
{[\mathrm{min}]}\end{array}$ & $\begin{array}{c}\text { 2h Flexural } \\
\text { strength } \\
{[\mathrm{MPa}]}\end{array}$ & $\begin{array}{c}\text { Absolute dry compressive } \\
\text { strength }[\mathrm{MPa}]\end{array}$ \\
\hline 100 & 0.35 & 9 & 12 & 7.6 & 61.3 \\
\hline
\end{tabular}

Table 2 The mechanical properties of $\alpha$ - high strength gypsum based tile adhesive

\begin{tabular}{ccccc}
\hline $\begin{array}{c}\text { 1d tensile bond } \\
\text { strength }[\mathrm{MPa}]\end{array}$ & $\begin{array}{c}\text { 3d tensile bond } \\
\text { strength }[\mathrm{MPa}]\end{array}$ & $\begin{array}{c}\text { 28d tensile bond } \\
\text { strength }[\mathrm{MPa}]\end{array}$ & $\begin{array}{c}\text { Volume change rate } \\
{[\%]}\end{array}$ & $\begin{array}{c}\text { Immersion tensile bond } \\
\text { strength [MPa] }\end{array}$ \\
\hline 0.6 & 0.9 & 1.9 & 0.17 & 0.52 \\
\hline
\end{tabular}

The matching adhesive is mainly prepared by $\alpha$-high strength gypsum. The main properties of $\alpha$-high strength gypsum are shown in Table 1 . It can be seen that $2 \mathrm{~h}$ flexural strength and absolute dry compressive strength of $\alpha$ - high strength gypsum are 7.6Mpa and $61.3 \mathrm{MPa}$, respectively. It is prepared by the flue gas desulfurization gypsum which has higher content of $\mathrm{CaSO}_{4}$ compared with natural gypsum.

The properties of the matching adhesive prepared by using $\alpha$-high strength gypsum are outlined in Table 2 .

\footnotetext{
*Corresponding author: 13811802011@139.com
} 


\subsection{Methods}

According to "Ceramic wall and floor tile adhesive" (JC/T 547), the tensile bond strength and water resistance of the matching adhesive are determined [7]. The dimensional stability is determined according to the corresponding provisions of "Gypsum based self-leveling compound for floor” (JC/T 1023).

\section{Result and discussion}

\subsection{The tensile bond strength of $\alpha$-high strength gypsum based adhesive}

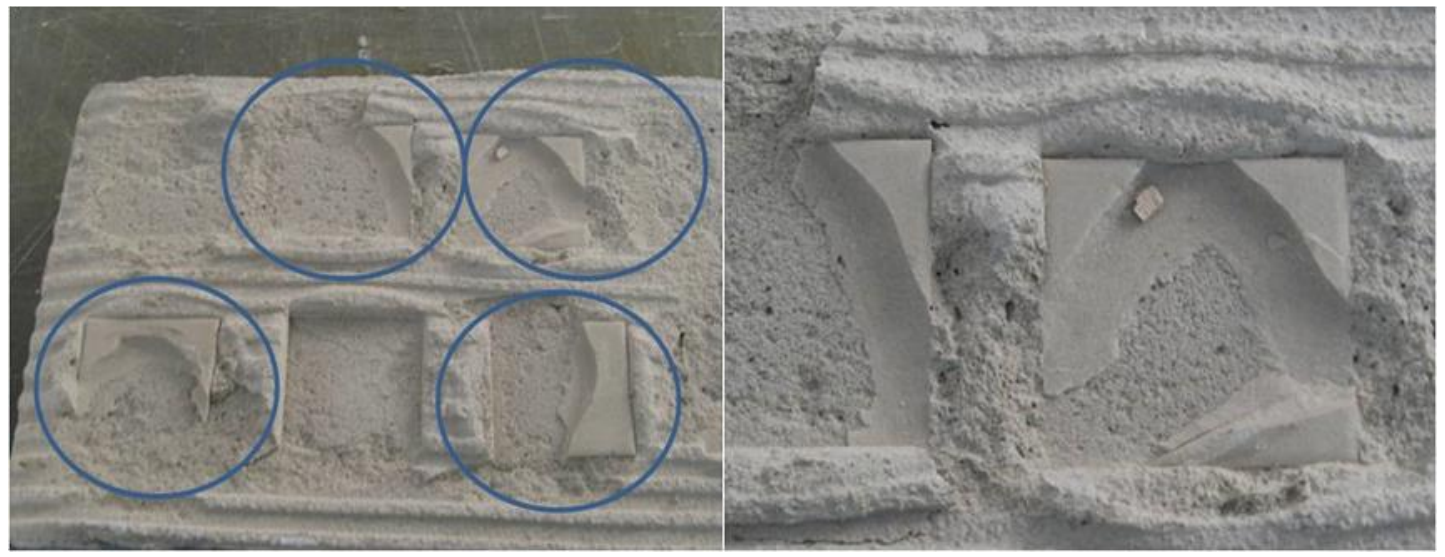

Fig.1 The fracture morphology between the matching adhesive and cement board substrate

The tensile bond strength of $\alpha$-high gypsum based adhesive at different ages is shown in Figure 2. The early strength of the gypsum based adhesive develops rapidly, and its original tensile bond strength in one day can reach $0.6 \mathrm{MPa}$. Moreover, the strength in 7 days is close to 1.5 $\mathrm{MPa}$, and it is close to $80 \%$ of 28 -day strength. The 28 -day original tensile bond strength is about $1.9 \mathrm{MPa}$, which is much higher than the $0.5 \mathrm{MPa}$ specified in the standard
(JC/T 547). The fracture morphology after the 28-day original tensile strength test is shown in Fig. 1. It can be seen that the gypsum-based adhesive has a good bond performance with the ceramic tile and cement board base, and there is no smooth peeling phenomenon in the interface layers. The operable time of the adhesive is 90 minutes and it is shorter than that of the cement-based adhesive.

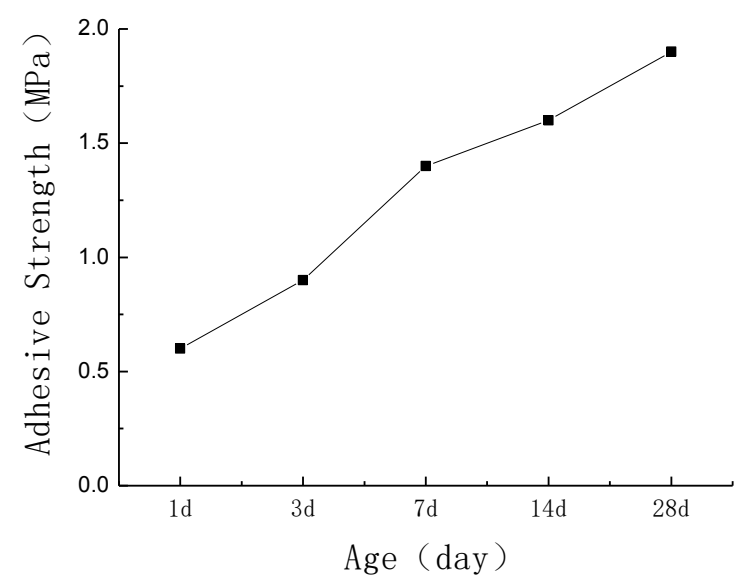

Fig.2 The tensile bond strength of adhesive at different ages 


\subsection{The dimensional stability of the gypsum-based adhesive}

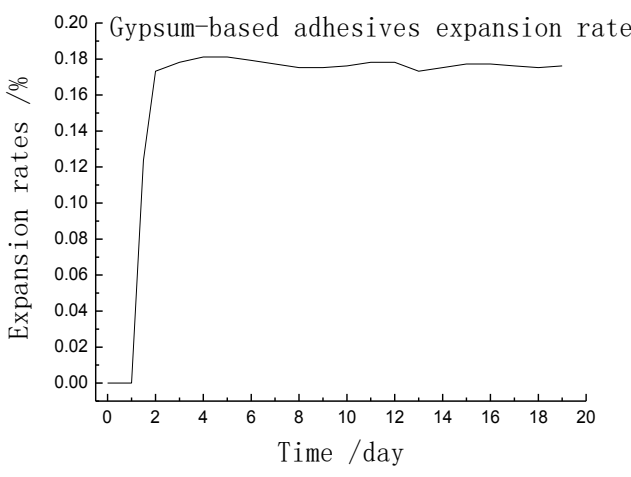

(a)

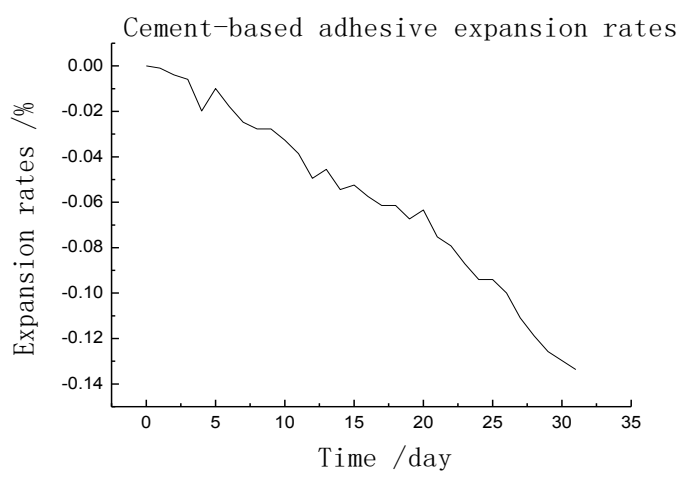

(b)

Fig.3 The linear expansion rate curves of gypsum-based adhesive (a) and cement-based adhesive (b) at different ages

In this paper, the dimensional stability is characterized by linear expansion rate. The linear expansion rate curves of gypsum-based adhesive and cement-based adhesive at different ages are shown in Fig. 3. It can be seen from Fig. 3 (a) that the gypsum-based adhesive exhibits very good dimensional stability. Within an hour, the gypsum-based adhesive swells slightly, with an expansion rate of about $0.17 \%$. As the age continues, there is no significant change, and the swelling rate fluctuates from about $0.16 \%$ to $0.18 \%$. Fig. 3 (b) is a curve of the linear expansion rate of the cement adhesive at different ages. There is a large difference in the expansion rate curves of cement-based adhesive and gypsum-based adhesive. With the increase of age, the cement adhesive hardened body has a more obvious shrinkage. Its 7-day and 28-day expansion change rates are $0.025 \%$ and $0.134 \%$, respectively, and as the age further increases, the cement adhesive hardened body may continue to shrink.
It is noting that the expansion of gypsum begins before the initial setting time and tends to stabilize in $48 \mathrm{~h}$. The expansion of gypsum does not generate significant internal stress because of the short expansion time. In addition, dimensional expansion usually generates compressive stress inside, which is more favorable to the stability of the hardened body than the tensile stress generated by dimensional shrinkage. The shrinkage of cement based adhesive runs through the whole curing age, and there is still a tendency to shrink after 28 days. Compared with cement-based adhesives, gypsum-based adhesive has obvious advantage in dimensional stability to avoid problems such as hollowness and falling off.

\subsection{The water resistance of the gypsum-based adhesive}

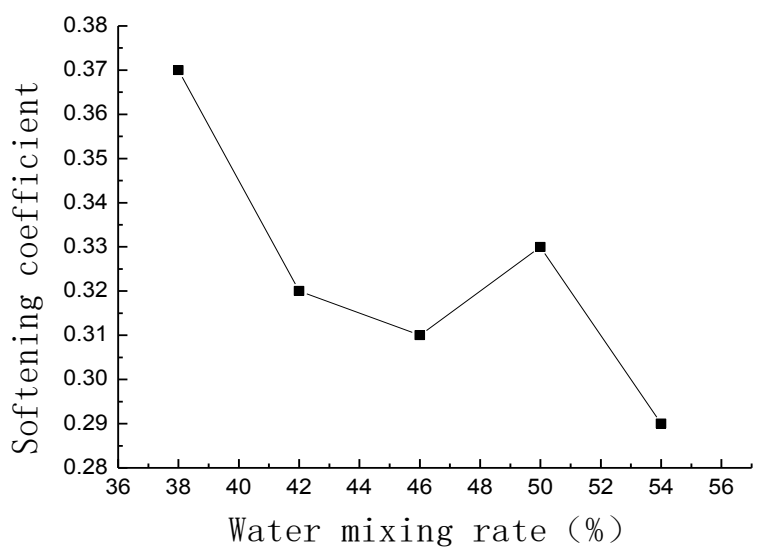

Fig.4. The relation curve between gypsum water mixing rate and softening coefficient

As is well known, gypsum-based gelling materials have a lower softening coefficient and poor water resistance. There is a lot of research ${ }^{[8-10]}$ to increase the water resistance of gypsum. However, gypsum has so far not been accepted as an outdoor material. The softening coefficient of gypsum decreases significantly with the increase of the water mixing rate. The relation curve between gypsum water mixing ratio and softening coefficient is shown in Fig. 4. The mixing water rate of $\alpha$-gypsum is usually $30 \%$ to $50 \%$, and $\beta$-gypsum is $60 \%$ to $70 \%$. Therefore, the softening coefficient of $\alpha$-gypsum is significantly higher than $\beta$-gypsum. It is difficult to meet the requirements of water resistance in JC / T 547 "Ceramic wall and floor tile adhesive", if the adhesive is 
prepared with $\beta$ - gypsum. With reference to this standard, the immersion tensile bond strength of $\alpha$-gypsum based ceramic tile adhesives is $0.40 \mathrm{MPa}$ to $0.55 \mathrm{MPa}$, which basically meets the requirements of the standard. Therefore, production of gypsum-based ceramic tile adhesive should use $\alpha$-high strength gypsum as raw material. And the joints should be waterproofed when they are pasted with this adhesive.

\subsection{Environmental performance}

Gypsum is a kind of green environment-friendly gelling material. The solidified porous structure can adjust the indoor humidity and make the living environment more comfortable. And gypsum is a material with a neutral $\mathrm{pH}$ value, so it is not easy to appear panning and other phenomena. The test results show that the gypsum-based tile adhesive has good environmental protection performance, in which the volatile organic content is not detected, and the internal and external exposure index is 0.1 , which is far lower than the standard value required for building material products.

\section{Engineering application}

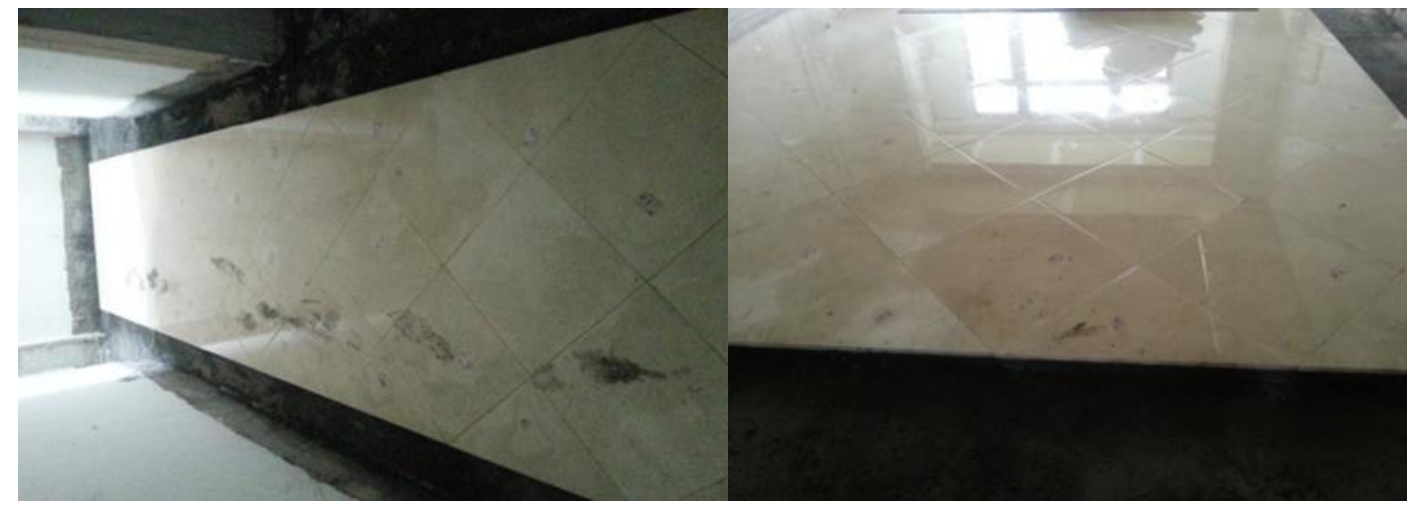

Fig.5 The application of gypsum-based adhesive used as wall covering and floor paving

Fig.5 shows the application case of gypsum-based tile adhesives. And these projects have been completed more than three years and no phenomenon of empty drum or falling off appears. The characteristics of gypsum-based tile adhesives determine that they can only be used for indoor application of vitrified tiles and stone. In addition, the gypsum-based adhesive has a relatively short open time. During the construction process, workers are required to strictly follow the operating rules to avoid the wrong operation of adding water and stirring after hardening.

\section{Conclusions}

The gypsum-based tile adhesive has advantages as follows:

The tensile bond strength can reach $1.9 \mathrm{MPa}$ in 28 days, and its strength develops rapidly, and it is close to $0.6 \mathrm{MPa}$ in one day.

Gypsum-based adhesive has better dimensional stability compared with cement-based adhesive, and has good compatibility with vitrified bricks and stone materials.

Using $\alpha$-high strength gypsum as raw material can increase the immersion tensile bond strength and meet the standard requirements. And the joints should be waterproofed when they are pasted with this gypsum-based adhesive.
The gypsum-based adhesive has a relatively short open time. During the construction process, workers are required to strictly follow the operating rules.

\section{Acknowledgements}

This work was financially supported by Beijing Special Fund for New Wall Materials Program.

\section{References}

1. A. Jenni, L. Hofner, R. zurbriggen. Influence of Polymers on Microstructure and Adhesive Strength of Cementitious Tile Adhesive Mortars. Cement and Concrete Research, 2005(1): 35.

2. Lv W. S. Research on the Bonding Ability of Tile Adhesive. Wall Materials Innovation \& Energy Saving in Buildings, 2019 (6): 54.

3. Kondratieva N, Barre M, Goutenoire F, et al. Study of Modified Gypsum Binder. Construction \& Building Materials, 2017(149): 535.

4. Fengliang Dong, Fenggang Shang, Degang Wan, et al. Application for Tile Adhesive in Interior Decoration Area. 2011 (10): 92.

5. Xiaojin Huang, Pin Shen, Pingan Zhou, C. N. Patent 108516763. (2018)

6. Boping $\mathrm{Fu}$, Jun Li, Xiaoping Chen, C. N. Patent 110511970. (2019) 
7. Xuyan Meng, Xuedang Xiao. Testing and Experimental Research on the Tensile Bond Strength of Cement-based Ceramic Tile Adhesive. New Building Materials, 2019 (11): 101.

8. Jian Fu. Effect of Portland Cement on Strength and Water Resistance of Building Gypsum. Non-Metallic Mines, 2019, 42 (5): 39.

9. Yinghao Yuan, Jiwei Cai, et al. Improving Effect of Aluminate Cement on Strength and Water Resistance of Gypsum-based Materials. Chemical Research, 2018, 29 (2): 208.

10. Zhixin Li, Jiahui Peng, et al. Study on Changes of Hydration Process, Strength and Waterproof Properties of Recycled Gypsum. Non-Metallic Mines, 2015 (5): 34. 